\title{
$9-2019$
}

\section{Measuring Bird Damage to Three Fruit Crops: A Comparison of Grower and Field Estimates}

Julie L. Elser

Catherine A. Lindell

Karen M. M. Steensma

Paul D. Curtis

Deanna K. Leigh

See next page for additional authors

How does access to this work benefit you? Let us know!

Follow this and additional works at: https://commons.und.edu/bio-fac

Part of the Agronomy and Crop Sciences Commons

\section{Recommended Citation}

Julie L. Elser, Catherine A. Lindell, Karen M. M. Steensma, et al.. "Measuring Bird Damage to Three Fruit Crops: A Comparison of Grower and Field Estimates" (2019). Biology Faculty Publications. 34.

https://commons.und.edu/bio-fac/34

This Article is brought to you for free and open access by the Department of Biology at UND Scholarly Commons. It has been accepted for inclusion in Biology Faculty Publications by an authorized administrator of UND Scholarly Commons. For more information, please contact und.commons@library.und.edu. 


\section{Authors}

Julie L. Elser, Catherine A. Lindell, Karen M. M. Steensma, Paul D. Curtis, Deanna K. Leigh, William F. Siemer, Jason Boulanger, and Stephanie A. Shwiff

This article is available at UND Scholarly Commons: https://commons.und.edu/bio-fac/34 


\title{
Measuring Bird Damage to Three Fruit Crops: A Comparison of Grower and Field Estimates
}

\author{
J. L. Elser ${ }^{\mathrm{a} *}$, C. A. Lindell ${ }^{\mathrm{b}}$, K. M. M. Steensma ${ }^{\mathrm{c}}$, P. D. Curtis ${ }^{\mathrm{d}}$, D. K. Leigh ${ }^{\mathrm{e}}$, W. F. Siemer ${ }^{\mathrm{d}}$, J. \\ R. Boulanger ${ }^{\mathrm{f}}$, and S. A. Shwiff ${ }^{\mathrm{a}}$
}

${ }^{a}$ USDA/APHIS/WS National Wildlife Research Center, 4101 LaPorte Ave., Fort Collins, CO 80521, USA

${ }^{\mathrm{b}}$ Michigan State University, 1405 S. Harrison Rd., East Lansing, MI 48823, USA

${ }^{\mathrm{c}}$ Trinity Western University, 7600 Glover Road, Langley, BC V2Y 1Y1, Canada

${ }^{\mathrm{d}}$ Cornell University, 226 Mann Drive, Cornell University Ithaca, New York 14853, USA

${ }^{\mathrm{e}}$ Western Washington University, 516 E College Way, Bellingham, WA 98225, USA

${ }^{\mathrm{f}}$ University of North Dakota, 10 Cornell Street, Grand Forks, ND 58202, USA

*Corresponding author: Julie.L.Elser@usda.gov, ph: (970) 266-6190

\begin{abstract}
Birds are common pests in fruit orchards. They frequently consume and damage fruit resulting in decreased yields for growers. The true extent of damage is difficult to measure. Producer surveys are often implemented to estimate damage, but the accuracy of these estimates is uncertain. We compared damage estimates obtained through field studies with estimates from a producer survey for three fruit crops: wine grapes, sweet cherries, and 'Honeycrisp' apples. We also analyzed relationships between use of various damage management methods and levels of bird damage. We found wine grape and sweet cherry growers accurately assessed bird damage, while 'Honeycrisp' apple growers may overestimate damage. Growing region appears to be an important damage predictor for wine grape and sweet cherry crops. Significant relationships between management methods and damage were positive, suggesting growers only use these methods when bird damage is substantial.
\end{abstract}

Keywords: bird damage, sweet cherries, 'Honeycrisp' apples, wine grapes, damage estimates 


\section{Introduction}

Bird damage to fruit crops is a significant concern for growers (Dolbeer et al. 1994, Lindell et al. 2012), causing millions of dollars in lost yield each year (Anderson et al. 2013). In addition to consumption, birds may damage fruit, leaving it susceptible to infection and reducing quality (Dellamano 2006). Based on our field work in sweet cherries, wine grapes, and "Honeycrisp" apples in Michigan, New York and the Pacific Northwest, bird species commonly causing damage include American robins (Turdus migratorius), European starlings (Sturnus vulgaris), house finches (Haemorhous mexicanus), Cedar waxwings (Bombycilla cedrorum), and American crows (Corvus brachyrhynchos); the most commonly detected pest bird species vary by crop and region (Anderson et al. 2013, Hannay et al. 2019). Growers use a variety of bird management methods to reduce damage to their crops (Conover 2001, Tracey et al. 2007, Steensma et al. 2016), increasing production and benefiting consumers (Anderson et al. 2014, Elser et al. 2016).

The true extent of crop damage caused by wildlife is often uncertain. Estimates of damage generally come from one of two sources: field studies conducted by trained biologists, or surveys distributed to crop producers. Each method has advantages and disadvantages. Field studies are often assumed to provide greater accuracy, but are expensive and time-consuming to conduct. Producer surveys allow larger areas to be studied, but raise questions of possible bias or inaccuracy. Few studies have directly compared field estimates of damage with grower estimates of damage (Tzilkowski et al. 2002, Johnson-Nistler et al. 2005, Humberg et al. 2007). However, these studies all focused on ground-level crops that were mainly depredated by rodents, deer, and other mammals. There has not been a similar study that evaluates grower perceptions of bird damage to fruit crops in comparison with estimates from field studies. 
Birds are unique pests because they are highly mobile, which may result in greater spatial and temporal variation in damage levels than with mammalian pests. In addition, large numbers of bird species can be detected in fruit crops although species vary in the likelihood they cause crop damage (Lindell et al. 2012, Hannay et al. 2019). These factors could influence growers' perceptions of the abundance of birds that cause damage and actual damage levels. Determining the accuracy of grower estimates will aid in the optimal distribution of resources for future study, and for cost-effective choices of bird management techniques. For example, if grower estimates are reasonably accurate, it will generally be easier and less costly to rely on those estimates than to conduct field surveys.

Our goal was to compare bird damage estimates obtained by wildlife biologists during field studies with grower estimates reported via a self-administered mail survey. We included three specialty fruit crops in this study: 'Honeycrisp' apples (Malus x domestica), sweet cherries (Prunus avium), and wine grapes (Vitis vinifera L.). Additionally, we examined the use of bird damage management methods in relation to extent of bird damage.

\section{Methods}

\section{Grower Perception of Bird Damage}

A self-administered mail survey was distributed to fruit growers in Michigan, New York, Oregon, Washington, and California in spring 2012, targeting producers of 'Honeycrisp' apples, blueberries, wine grapes, and sweet and tart cherries. A thorough description of survey methods are reported in Anderson et al. (2013). In short, the authors used Dillman's (2000) Total Design Method to increase respondent sample size, including a respondent-friendly questionnaire, multiple contacts via United States Postal Service mail, and a cover letter that personalized 
correspondence. The survey instrument consisted of 21 questions soliciting information about acreage, yield, estimates of bird damage, and any bird damage management methods used. Bird damage estimates were reported as percent of crop lost due to birds. A total of 7,666 surveys were distributed and 2,351 completed surveys were returned for a $30.7 \%$ response rate. Bird damage estimates obtained from field studies, described in the next section, were available for sites in Michigan, New York, and the Pacific Northwest (PNW), but not California, so survey data from California were omitted (survey data from Oregon and Washington were combined into one region: PNW). Additionally, survey observations in which producers stated that they took action to manage bird damage but did not specify which techniques they used were omitted, and observations that did not include an entry for percentage of yield damaged were omitted. The final sample size after omissions was 904 surveys. All survey responses refer to the 2011 growing season.

\section{Field Estimates of Bird Damage}

Field trials were conducted in three states (MI, NY, and WA) from 2012 through 2014, and those methods are thoroughly described in (Lindell et al. 2016). Data provided for this study were from 2012 and 2013 and included sweet cherries, 'Honeycrisp' apples, and wine grapes. Some sites were measured in both 2012 and 2013. Field estimates of bird damage were reported as percent damage per block. Any bird management method used at individual sites was recorded. Although field estimates of bird damage were obtained from the same regions as the survey estimates for all crops, we note that field and survey estimates refer to different years and different fields.

Statistical Analyses 
We tested grower and field estimates for each cropby region for normality. Histogram and Q-Q plots indicated nonparametric distributions for all data sets. Therefore, we performed MannWhitney U Tests to determine whether the distributions of the two sets of damage estimates were different for each crop by region. We performed linear regression analyses to determine the effects of damage management methods and growing region on damage estimates as well as any impact of type of estimate (field or survey) on damage estimates. The dependent variable (percent damage estimated) was a continuous variable. All other variables were dummy (binary) variables. We removed repeated field assessments (plots measured in two years) from the samples for regression analyses. Management methods were chemical repellents, lethal shooting, trapping, exclusion netting, auditory scare devices, visual scare devices, and predator nest boxes, with a category for other methods. We only considered American kestrel falcon (Falco sparverius) nest boxes as a management method in sweet cherry crops, since these potentially beneficial predators have completed nesting by the time wine grapes and 'Honeycrisp' apples are ripening and are no longer consistently near the nest box to deter fruit-eating birds (e.g., Shave et al. 2018). All statistical analyses were performed using R (R Core Team 2017) using a 0.05 alpha level.

\section{Results}

For all three crops and regions, damage estimates showed a similar pattern of survey estimates being higher than field estimates (Table 1). Field and survey damage estimates were not significantly different in wine grapes or in sweet cherries in Michigan and New York, but were significantly different in sweet cherries in the PNW and in 'Honeycrisp' apples in all regions (Mann-Whitney U Tests, Table 2). 
Table 1. Descriptive statistics for field and survey bird damage estimates in terms of percentage of crop lost to birds. $\mathrm{N}=$ number of respondents.

A. Wine grape

\begin{tabular}{lrrrrrrrr}
\hline & \multicolumn{3}{c}{ Field } & & \multicolumn{3}{c}{ Survey } \\
\cline { 2 - 4 } \cline { 7 - 9 } & \multicolumn{1}{c}{ MI } & NY & PNW & & MI & NY & PNW \\
\hline \hline N & 21 & 30 & 29 & & 71 & 126 & 23 \\
Mean & 7.34 & 3.46 & 6.97 & & 10.23 & 6.54 & 7.28 \\
Median & 3.75 & 2.11 & 1.99 & & 5.00 & 3.00 & 5.00 \\
St Dev & 10.10 & 3.42 & 11.99 & & 15.61 & 10.09 & 7.76 \\
\hline
\end{tabular}

B. Sweet cherry

\begin{tabular}{lrrrrrrr}
\hline & \multicolumn{3}{c}{ Field } & & \multicolumn{3}{c}{ Survey } \\
\cline { 2 - 4 } \cline { 7 - 9 } & \multicolumn{1}{c}{ MI } & NY & PNW & & MI & NY & PNW \\
\hline \hline N & 33 & 20 & 34 & & 119 & 71 & 227 \\
Mean & 10.07 & 27.54 & 3.66 & & 15.52 & 28.63 & 8.63 \\
Median & 6.11 & 16.48 & 1.68 & & 10.00 & 20.00 & 5.00 \\
St Dev & 11.32 & 28.82 & 7.30 & & 21.57 & 27.14 & 13.32 \\
\hline
\end{tabular}

C. 'Honeycrisp' apple

\begin{tabular}{lrrrrrrrr}
\hline & \multicolumn{3}{c}{ Field } & & \multicolumn{3}{c}{ Survey } \\
\cline { 2 - 4 } \cline { 7 - 9 } & \multicolumn{1}{c}{ MI } & NY & PNW & & MI & \multicolumn{1}{c}{ NY } & PNW \\
\hline \hline N & 25 & 32 & 33 & & 103 & 113 & 51 \\
Mean & 2.64 & 1.81 & 1.71 & & 4.05 & 5.83 & 8.77 \\
Median & 0.59 & 0.52 & 1.01 & & 2.00 & 2.00 & 5.00 \\
St Dev & 6.47 & 5.05 & 2.15 & & 6.34 & 11.69 & 14.61 \\
\hline
\end{tabular}

Table 2. Mann-Whitney U Test p-values comparing bird damage estimates obtained from grower surveys and field studies. Significant $p$-values are in bold.

\begin{tabular}{lrrr} 
Region & Wine grape & Sweet cherry & 'Honeycrisp' apple \\
\hline MI & 0.7440 & 0.3286 & $\mathbf{2 . 9 1 E - 0 2}$ \\
NY & 0.4306 & 0.6209 & $\mathbf{2 . 0 9 E - 0 4}$ \\
PNW & 0.5301 & $\mathbf{9 . 9 0 E - 0 6}$ & $\mathbf{1 . 1 6 E - 0 3}$ \\
\hline
\end{tabular}

Regression analyses indicated the source of the estimate (field or survey) was not a predictor of damage level for wine grapes and sweet cherries (Table 3). For 'Honeycrisp' apples, damage estimates originating from the survey were predicted to be about 3.5 percentage points higher 
than field estimates $(\mathrm{p}=0.0112)$. Region was an important predictor of damage for sweet cherries, with orchards in New York experiencing damage about 11 percentage points higher than orchards in Michigan, and orchards in PNW experiencing damage about seven percentage points lower than orchards in Michigan, generally corresponding with results from Lindell et al. (2016). Vineyards in New York were predicted to experience about four percentage points less damage than vineyards in Michigan. Region did not appear to be an important predictor of damage for 'Honeycrisp' apples, in line with results from Lindell et al. (2016).

Exclusion netting was positively associated with damage level in both wine grape and sweet cherry crops. Damage levels in 'Honeycrisp' apple orchards were positively associated with use of two bird damage management methods: chemical repellents and lethal shooting.

Table 3. Regression results with damage estimates as the dependent variable. Reference case is field estimates in Michigan using no bird damage management methods. Significant p-values are in bold.

\begin{tabular}{lrrrrrr} 
& \multicolumn{2}{c}{ Wine grape } & \multicolumn{2}{c}{ Sweet cherry } & \multicolumn{2}{c}{ 'Honeycrisp' apple } \\
\hline Variable & Estimate & p-value & Estimate & p-value & Estimate & p-value \\
\hline \hline Intercept & $\mathbf{7 . 0 1 6 9}$ & $\mathbf{0 . 0 0 1 9}$ & $\mathbf{1 2 . 3 9 3 6}$ & $\mathbf{1 . 4 E - 0 6}$ & -0.5048 & 0.7347 \\
Survey & 0.7379 & 0.6928 & -0.1616 & 0.9486 & $\mathbf{3 . 5 4 6 2}$ & $\mathbf{0 . 0 1 1 2}$ \\
New York State & $\mathbf{- 3 . 5 9 6 3}$ & $\mathbf{0 . 0 2 4 0}$ & $\mathbf{1 1 . 4 1 6 3}$ & $\mathbf{9 . 9 E - 0 6}$ & 1.6322 & 0.1702 \\
Pacific Northwest & -2.0573 & 0.3450 & $\mathbf{- 7 . 1 7 9 4}$ & $\mathbf{0 . 0 0 0 5}$ & 2.4140 & 0.1257 \\
Chemical Repellents & -0.4058 & 0.9160 & 3.7531 & 0.0783 & $\mathbf{1 2 . 6 5 3 2}$ & $\mathbf{8 . 6 E - 0 5}$ \\
Lethal Shooting & 3.4251 & 0.0683 & 3.2838 & 0.0937 & $\mathbf{3 . 1 9 4 8}$ & $\mathbf{0 . 0 3 1 8}$ \\
Trapping & -4.8549 & 0.4193 & -3.6813 & 0.2310 & -2.5437 & 0.3987 \\
Exclusion Netting & $\mathbf{3 . 1 6 3 0}$ & $\mathbf{0 . 0 3 4 3}$ & $\mathbf{9 . 1 2 5 7}$ & $\mathbf{0 . 0 1 0 5}$ & -3.3434 & 0.5122 \\
Auditory Scare Device & -1.4436 & 0.3868 & 1.8426 & 0.3289 & 0.1365 & 0.9270 \\
Visual Scare Device & 2.4542 & 0.1440 & 1.9435 & 0.3200 & 2.9763 & 0.0605 \\
Predator Nest Box* & & & -2.6184 & 0.2335 & & \\
Other & 0.4761 & 0.9055 & 2.7388 & 0.5276 & 1.4180 & 0.5973 \\
\hline R-squared & 0.07 & \multicolumn{5}{c}{0.13} \\
\hline
\end{tabular}

*Predator nest boxes were not considered for wine grapes and 'Honeycrisp' apples. 


\section{Discussion and Conclusions}

The results of this study suggest accuracy of producer estimates of damage is dependent on crop type and growing region, with more accurate estimates associated with crops of shorter stature and smaller fruit size. Both statistical analyses revealed no significant difference between fieldand survey-derived estimates when applied to wine grape estimates in all regions and sweet cherry estimates in two of three regions. In contrast, 'Honeycrisp' apple estimates in all regions and sweet cherry estimates in the PNW varied significantly between field and grower damage estimates. This disparity may result from the height difference of the crop or the size of the fruit. Wine grapes are generally grown at eye-level, while many fruit trees are not. This means wine grape growers can assess their crop at eye-level, while sweet cherry growers and some apple growers generally assess damage from the ground where they cannot easily see all of the fruit, and may infer damage that does not exist. Both apples and cherries, when not trellised, are of a size and stature that not only make it more difficult for growers to assess damage visually, but also make it easier for birds to nest and hide, which could potentially affect grower perception of bird numbers. Additionally, apples are much larger than cherries or grapes, so a few damaged apples may be more obvious than a similar number of smaller damaged fruit. Apples likely are susceptible to damage from a smaller range of bird species, given their size and hardness, potentially leading to "spottier" damage patterns, i.e., damage varying greatly from place to place. This may make it more difficult for growers to accurately assess bird damage. Finally, producer damage estimates are more likely to overestimate than underestimate damage when seeing a few obviously damaged apples.

Several bird damage management methods were positively associated with damage estimates, possibly because these methods are only employed when damage is severe. Previous work 
indicates that bird management methods can be quite variable in success, deterring birds and reducing crop damage at some times and locations, but ineffective in others (e.g., Anderson et al. 2013, Firake et al. 2016, Shave et al. 2018, Lindell et al. 2018). Thus, growers may not be willing to invest in bird management unless the damage is a significant problem.

Relatively few studies have compared growers' estimates of wildlife damage to estimates derived from field studies. Tzilkowski et al. (2002) compared on-the-ground sampling and grower questionnaire estimates of wildlife damage to corn, primarily caused by white-tailed deer (Odocoileus virginianus). In this study, growers received a questionnaire when field sampling took place in their crops. A $69 \%$ response rate was achieved, with farmers estimating $9.7 \%$ corn loss and field studies estimating $7.7 \%$ corn loss. The authors did not find a statistically significant difference between the two sets of estimates.

Johnson-Nistler et al. (2005) conducted a similar study on damage caused by Richardson's ground squirrels (Urocitellus richardsonii) to alfalfa crops. They sent a five-question survey instrument to 496 alfalfa growers in Montana and achieved a 58\% response rate. They also conducted field studies at two sites in southwest Montana using wire mesh exclosures to create protected areas. Growers estimated that alfalfa production was reduced $24 \%$ in areas where ground squirrels were present, while field studies found a $31 \%$ reduction in yield. The authors concluded that growers' estimates of damage were similar to or possibly lower than field estimates.

Most recently, Humberg et al. (2007) surveyed corn and soybean growers in Indiana to ascertain which wildlife species producers perceived as causing damage to crops, in addition to conducting field studies. The main damage-causing species were raccoons (Procyon lotor), white-tailed 
deer, and groundhogs (Marmota monax). Achieving a 26\% response rate, the authors concluded that growers could reasonably assess whether they experienced crop damage due to wildlife, but could not accurately identify the species of wildlife responsible for that damage.

The aforementioned studies are a few examples in a paucity of literature on this topic, and we found no studies that specifically examined bird damage estimates. Accurate estimates of bird damage to crops are vital to understanding the magnitude of the impact and to inform decisions regarding use of damage management methods. Ideally, we would have survey and field estimates from the same fields in the same years. However, we believe the large number of both grower estimates and field estimates across several regions provide general patterns of bird damage which can be used for a comparison of the two methods. We do not believe there were any systematic and differing biases represented by the farmers who either chose to participate in the survey or allowed us to collect field data. We did not seek out farms for field surveys that had a history of significant bird damage; for example, the estimates of bird damage for 15 blocks of wine grapes in Michigan in 2012 ranged from $0.2 \%$ to 38.3\% (Lindell et al. 2018). It is possible that farmers who participated in the survey and allowed field estimates were more interested in this issue than other farmers but, if this is the case, the same bias would have been present in both the survey and field results.

In two of the three crops in our study, grower and field estimates did not differ significantly, indicating growers of short stature crops like grapes and some taller crops like sweet cherries, with small fruit size, provide reasonably good estimates of bird damage. Although additional comparative data and analyses would be useful, the findings of this study show that grower estimates of bird damage are a valuable source of information. 


\section{Acknowledgements}

Funding for this study was provided by the United States Department of Agriculture's Specialty Crop Research Initiative. The authors would like to thank S. Wieferich, B. Hawes, R. Eaton, and

J. E. Carroll for their expertise and contribution to implementation of the producer survey and assistance with field studies. The authors are also grateful to numerous fruit growers who provided access to their fields as well as numerous field assistants. 


\section{References}

Anderson, A., C. Lindell, K. M. Moxcey, W. Siemer, G. M. Linz, P. Curtis, J. Carroll, C. Burrows, J. R. Boulanger, and K. Steensma. 2013. Bird damage to select fruit crops: The cost of damage and the benefits of control in five states. Crop Protection 52:103-109.

Anderson, A., C. Lindell, W. Siemer, and S. Shwiff. 2014. The welfare impacts of bird damage and its control in California wine grape production. Journal of Wine Economics 9:153-170.

Conover, M. R. 2001. Resolving human-wildlife conflicts: the science of wildlife damage management. CRC press.

Dellamano, F. 2006. Controlling birds with netting: blueberries, cherries and grapes. New York Fruit Quarterly 14:3-5.

Dillman, D. A. 2000. Mail and internet surveys: The tailored design method. New York.

Dolbeer, R. A., N. Holler, and D. W. Hawthorne. 1994. Identification and control of wildlife damage. Research and management techniques for wildlife and habitats. The Wildlife Society, Bethesda, Maryland:474-506.

Elser, J., A. Anderson, C. Lindell, N. Dalsted, A. Bernasek, and S. Shwiff. 2016. Economic impacts of bird damage and management in US sweet cherry production. Crop Protection 83:9-14.

Firake, D., G. Behere, and S. Chandra. 2016. An environmentally benign and cost-effective technique for reducing bird damage to sprouting soybean seeds. Field crops research 188:74-81.

Hannay, M. B., J. R. Boulanger, P. D. Curtis, R. A. Eaton, B. C. Hawes, D. K. Leigh, C. A. Rossetti, K. M. Steensma, and C. A. Lindell. 2019. Bird species and abundances in fruit crops and implications for bird management. Crop Protection 120:43-49.

Humberg, L. A., T. L. DeVault, B. J. MacGowan, J. C. Beasley, and O. E. Rhodes Jr. Crop depredation by wildlife in northcentral Indiana. Proceedings of the National Wild Turkey Symposium, 2007.

Johnson-Nistler, C., J. Knight, and S. Cash. 2005. Considerations Related to Richardson's Ground Squirrel (Spermophilus richardsonii) Control in Montana. Agronomy journal 97:1460-1464.

Lindell, C., M. Hannay, and B. Hawes. 2018. Bird Management in Blueberries and Grapes. Agronomy 8:295.

Lindell, C. A., R. A. Eaton, E. M. Lizotte, and N. L. Rothwell. 2012. Bird consumption of sweet and tart cherries. Human-Wildlife Interactions 6:10.

Lindell, C. A., K. M. Steensma, P. D. Curtis, J. R. Boulanger, J. E. Carroll, C. Burrows, D. P. Lusch, N. L. Rothwell, S. L. Wieferich, and H. M. Henrichs. 2016. Proportions of bird damage in tree fruits are higher in low-fruit-abundance contexts. Crop Protection 90:40-48.

R Core Team. 2017. R: A Language and Environment for Statistical Computing. R Foundation for Statistical Computing, Vienna, Austria.

Shave, M. E., S. A. Shwiff, J. L. Elser, and C. A. Lindell. 2018. Falcons using orchard nest boxes reduce fruit-eating bird abundances and provide economic benefits for a fruit-growing region. Journal of Applied Ecology 55:2451-2460.

Steensma, K. M., C. Lindell, D. Leigh, C. Burrows, S. L. Wieferich, and E. Zwamborn. 2016. Bird damage to fruit crops: a comparison of several deterrent techniques. Pages 196-203 in Proceedings of the 27th Vertebrate Pest Conference. Newport Beach, California.

Tracey, J., M. Bomford, Q. Hart, G. Saunders, and R. Sinclair. 2007. Managing Bird Damage to Fruit and Other Horticultural Crops. Bureau of Rural Sciences, Canberra.

Tzilkowski, W. M., M. C. Brittingham, and M. J. Lovallo. 2002. Wildlife damage to corn in Pennsylvania: farmer and on-the-ground estimates. The Journal of wildlife management:678-682. 